\title{
Design of LED Lighting System Based on AC Bus Power Supply Mode with Low and Variable Frequency
}

\author{
H. Su \& Y.G. Jin* \& P. M. Zheng \\ Department of Electronic Information and Engineering, Yanbian University, Yanji 133000, China
}

Keywords: Low frequency; Variable frequency; AC bus power supply; Step-down capacitor; LED units.

\begin{abstract}
In this paper design of LED lighting system based on AC (alternating current) bus power supply mode with low and variable frequency is proposed. Mainframe output alternating current with $250 \mathrm{~V}$ effective value and $200 \mathrm{~Hz}$ low frequency by conversion after APFC rectification. Extension set adopting capacitor step-down mode supply electricity to 15 25W LED units. The circuit of capacitor step-down power supply has simple structure, low cost, output short circuit and less loss. As the frequency is increased from $50 \mathrm{~Hz}$ to $200 \mathrm{~Hz}$, smaller capacity capacitor can be used to provide greater power, and the output voltage ripple is greatly reduced. Because of $200 \mathrm{~Hz}$ low frequency current, the power supply system has less EMI, stable work, low cost and simple maintenance.
\end{abstract}

\section{Introduction}

In the existing LED lighting system, current drives each lamp after rectification, filtering and DC-DC converter. So every converter releases $50 \sim 100 \mathrm{KHz}$ high-frequency wave to the space, it causes EMI and brings bad influence on health ${ }^{[1]}$. The structure of the system is complex and has high cost.

LED lighting system based on AC bus power supply mode with low and variable frequency has mainframe and extension set. Mainframe outputs alternating current with 250V effective value and $200 \mathrm{~Hz}$ low frequency by conversion after APFC rectification to the extension sets. Extension set is LED units, it adopting capacitor step-down mode supplies electricity to 15 25W LED units.

The circuit of capacitor step-down regulated power supply has simple structure, low cost, output short circuit and less loss ${ }^{[2-3]}$, but it needs large capacitor and has high voltage ripple ${ }^{[4]}$ when works in $50 \mathrm{~Hz}$. the working frequency is increased to $200 \mathrm{~Hz}$, so the lighting system can provide larger power and output smaller voltage ripple even use smaller capacitor. Because of $200 \mathrm{~Hz}$ low frequency current, the power supply system has less EMI, stable work, low cost and simple maintenance.

\section{Design of extension set}

\section{The whole block diagram of extension set}

Extension set model is shown as figure 1. It uses capacitive reactance to reduce voltage. The capacitive reactance is expressed as follow:

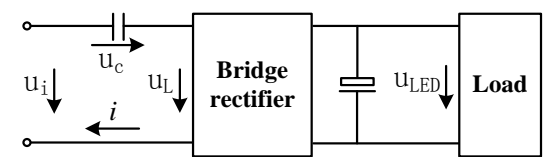

Fig.1 Block diagram of extension set

$$
Z_{C}=\frac{1}{2 \pi f C}
$$

Figure 2 shows the relation between capacitive reactance and frequency. The capacitive reactance obviously decreases when the frequency increases to $300 \mathrm{~Hz}$ even if capacitor capacity is different. Therefore the higher the frequency is, the larger the provided power is, and the relation has nonlinear characteristics. 


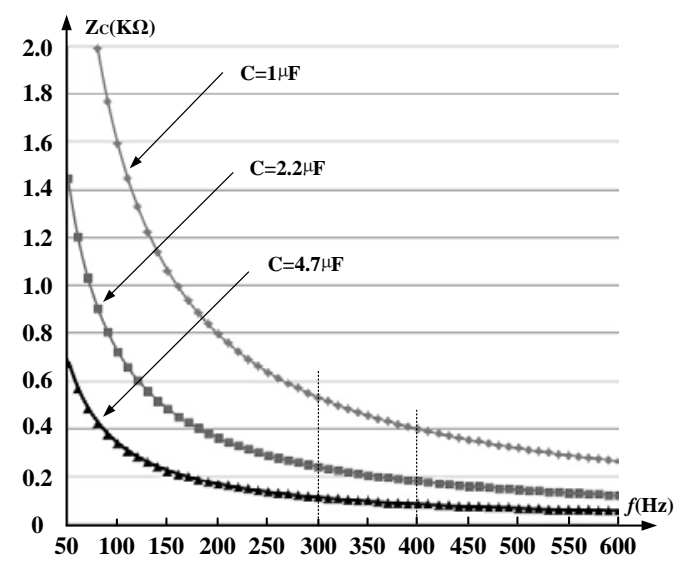

Fig.2 The relation curve between capacitive reactance and frequency

The capacitor current is continuous when input voltage is all added into the capacitor like above situation. But the current is discontinuous because of output voltage $\mathrm{u}_{\mathrm{L}}$ as shown in figure $1^{[5] \text {. }}$ Figure 3 is the waveform of current and power. So we should derive the relationship between output power and frequency and observe the changes of its characteristics.

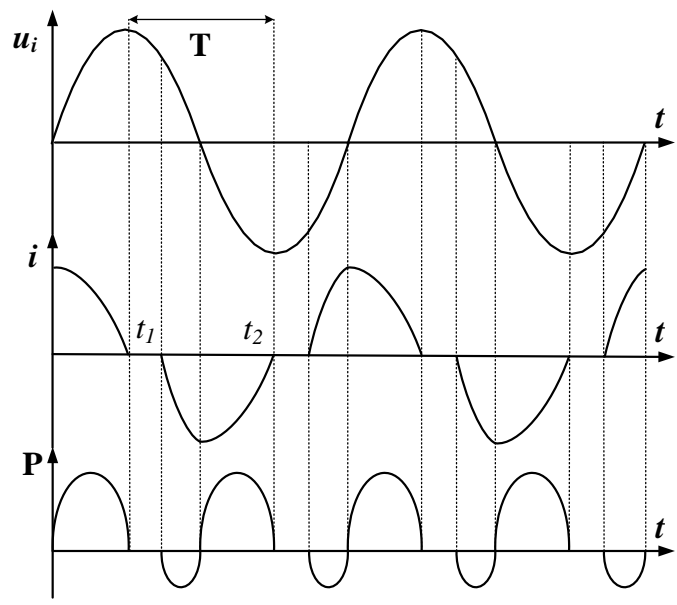

Fig.3 The waveform of current and power in circuit

\section{The relation of output power and frequency}

In extension set model, instantaneous power of the load is described as below.

$$
p=-u_{L} i
$$

Capacitor voltage and current are described as below, respectively.

$u_{c}=u_{i}-u_{L}$

$i=C \frac{d u_{c}}{d t}$

In formula (3) $\mathrm{u}_{\mathrm{i}}=U_{\max } \sin \omega t$, put formula (3) into (4), current can be known as formula (5).

$i=C U_{\text {max }} \omega \cos \omega t$

So the instantaneous power finally can be derived from formula (2) and formula (5).

$p=-u_{L} \omega C U_{\text {max }} \cos \omega t$

The average power can be written as formula (7) in the current conduction time t1 t2.

$P=-\frac{1}{T} \int_{t_{1}}^{t_{2}} C U_{\max } u_{L} \omega \cos \omega t d t$

$=u_{L} C U_{\text {max }}\left(\sin \omega t_{1}-\sin \omega t_{2}\right) / T$

In figure $3, \sin \omega t_{2}=-1$ at t2 moment, and $u_{L}=\left(U_{\max }-u_{L}\right)-U_{\max } \sin \omega t_{1}$ at $\mathrm{t} 1$ moment, so we can derive formula (8).

$\sin \omega t_{1}=1-2 u_{L} / U_{\text {max }}$

Formula (7) can be written as formula (9). Because $\mathrm{u}_{\mathrm{L}}$ is LED units voltage, it changes little. 


$$
P=2 u_{L} C\left(U_{\max }-u_{L}\right) / T
$$

Figure 4 is relation curve of power and frequency when the capacitor capacity is different. The higher the frequency is, the larger the output power is and the better the filtering effect is after rectification, but the $\mathrm{AC}$ voltage drop and the risk of series resonance on the power supply line increase at the same time. When $\mathrm{C}=1 \mu \mathrm{F}$, effective value $\mathrm{U}=250 \mathrm{~V}$ (Umax $=353 \mathrm{~V}$ ), $\mathrm{u}_{\mathrm{L}}=120 \mathrm{~V}$, $\mathrm{P} \approx 22 \mathrm{~W}$, the frequency is $200 \mathrm{~Hz}$.

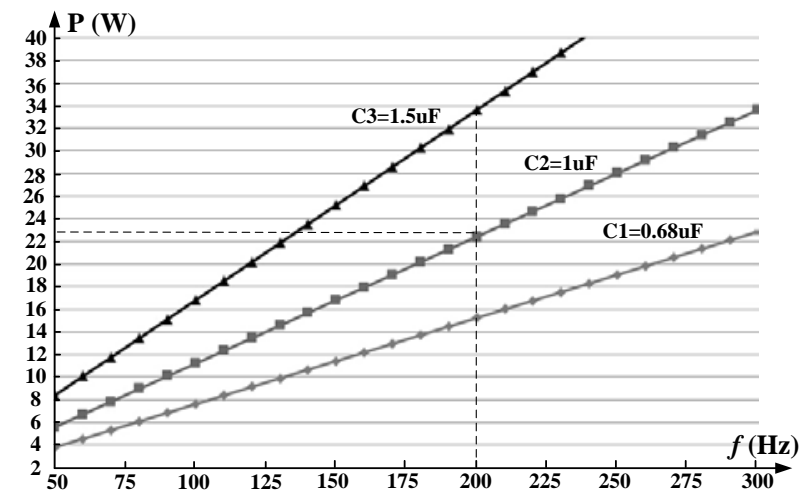

Fig.4 The relation of power and frequency

\section{Analysis of voltage drop on cable line}

The cable line has loss because of wiring resistance. The maximum load flow of commonly used $2.5 \mathrm{~mm}^{2}$ copper wiring is $23 \mathrm{~A}$, and its resistivity $\rho$ is $0.0185 \Omega \mathrm{mm} 2 / \mathrm{m}$ at $30^{\circ} \mathrm{C}$. According to $\mathrm{R}=\rho \mathrm{L} / \mathrm{S}$, the resistance of $100 \mathrm{~m}$ cable line is $0.74 \Omega$.

In the small lighting system, for example, a $200 \mathrm{~m}^{2}$ of classroom is usually installed $18 \sim 2040 \mathrm{~W}$ lamp, the total power is $800 \mathrm{~W}$, and wring length is short. Assuming that line voltage drop was less than $20 \mathrm{~V}$ and valid value of input voltage is $230 \mathrm{~V} \sim 250 \mathrm{~V}$, each lamp could normally work with constant power. The apparent power of this design is $2500 \mathrm{VA}$, and the active power is $1025 \mathrm{~W}$ when power factor is 0.41 , sufficient to meet the above requirements.

In order to analyze the maximum wring voltage drop, assuming that there were 40 lamps in the lighting system, and there was a lamp every five meters, wiring resistance would be $0.037 \Omega$, the cable line is $200 \mathrm{~m}$, we can obtain formula (10) from the model shown in figure 5.

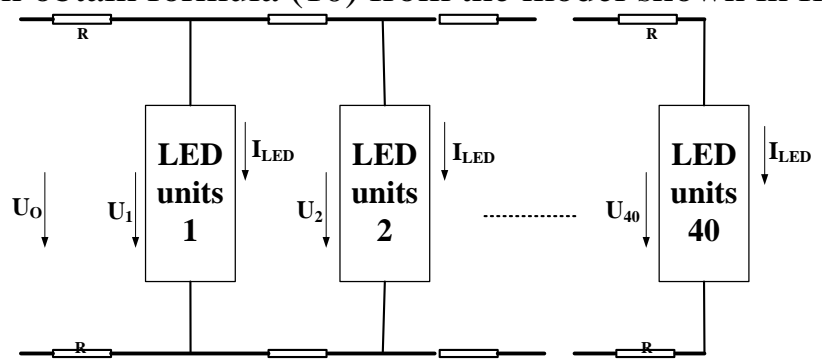

$$
\left(\begin{array}{l}
\bar{U}_{39}-\bar{U}_{40}=2 R \bar{I}_{L E D} \\
\bar{U}_{38}-\bar{U}_{39}=2 R\left(2 \bar{I}_{L E D}\right) \\
\vdots \\
\bar{U}_{1}-\bar{U}_{2}=2 R\left(39 \bar{I}_{L E D}\right) \\
\bar{U}_{0}-\bar{U}_{1}=2 R\left(40 \bar{I}_{L E D}\right)
\end{array}\right)
$$

Fig.5 The maximum voltage drop model

So we can know the maximum voltage drop from formula (11), the inductance of cable line can be negligible.

$$
\bar{U}_{0}-\bar{U}_{40}=2 R \bar{I}_{L E D}(1+2+3 \cdots+40)
$$

When $\mathrm{f}=200 \mathrm{~Hz}, \mathrm{U}=250 \mathrm{~V}, \mathrm{P} \approx 22 \mathrm{~W}$, the working current $\mathrm{I}_{\mathrm{LED}}$ of every lamp is about $0.27 \mathrm{~A}$, so the maximum voltage drop of cable line is $16.4 \mathrm{~V}$ according to formula (7).

\section{The determination of optimal voltage to drive LED units}

Figure 6 is the simulation curve of $P$ and $u_{L}$ under the condition of $C=1 \mu F, f=200 \mathrm{~Hz}$ according to formula (9). The curve shows that effective voltage value is $230 \mathrm{~V}, 240 \mathrm{~V}$ and $250 \mathrm{~V}$, respectively. 


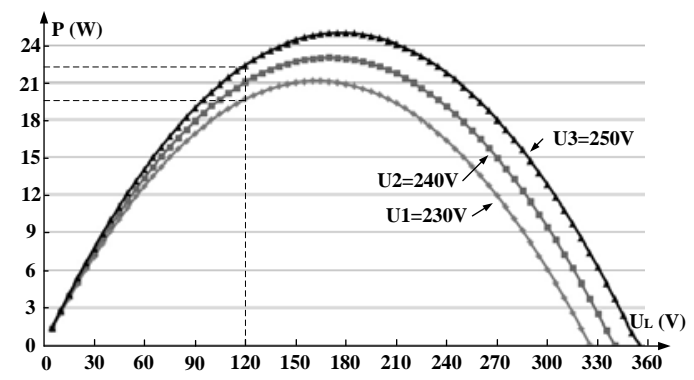

Fig.6 Simulation curve of output power and output voltage

On the left side of the maximum power point, the smaller $\mathrm{u}_{\mathrm{L}}$ is, the more stable $\mathrm{P}$ is, characteristic of constant power is good, but power factor gets smaller. On the right side of the maximum power point, the bigger $\mathrm{u}_{\mathrm{L}}$ is, the more $\mathrm{P}$ changes, but power factor gets bigger. The measured relation curve of $\mathrm{u}_{\mathrm{L}}$ and power factor is figure 7 .

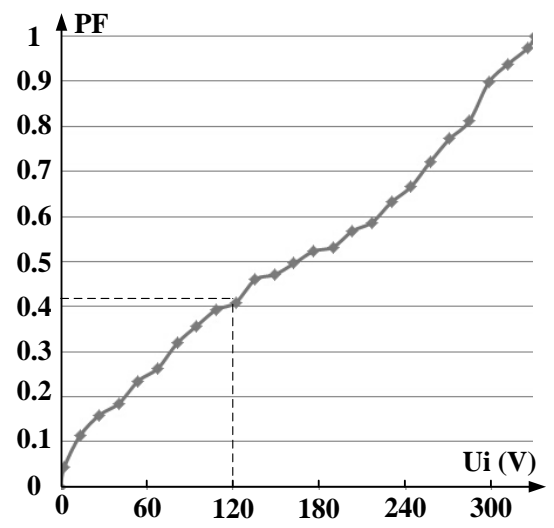

Fig.7 The relation curve of $\mathrm{u}_{\mathrm{L}}$ and power factor

Therefore LED units achieve constant power to drive when the working voltage is about $120 \mathrm{~V}$. Voltage of the LED units gets smaller as the temperature rise and power is also automatically reduced. This power supply has excellent characteristics to protect the load.

\section{Design of LED units driving circuit}

LED units driving circuit is shown as figure 8. The voltage of each SMD LED is about 3.1V and working current is $60 \mathrm{~mA}$. The voltage of each series with $38 \mathrm{LED}$ is $118 \mathrm{~V}$ and power is $7.1 \mathrm{~W}$, so lighting power can reach $21 \mathrm{~W}$ with three series in parallel connection. R2, R3 and R4 are equalizing resistors to make the LED current approximately equal. R1 is current limiting resistor to reduce impact current when connect to power supply and the ringing effect, it can improve the current waveform.

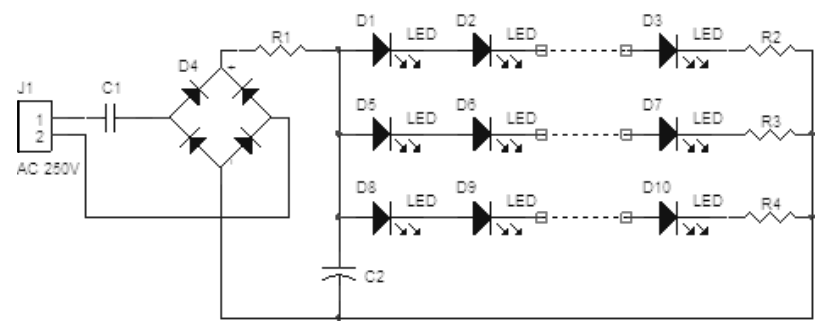

Fig.8 The driving circuit of LED units

\section{Design of mainframe's AC power supply with low and variable frequency}

The whole block diagram of mainframe

Figure 9 is the whole block diagram of mainframe. 


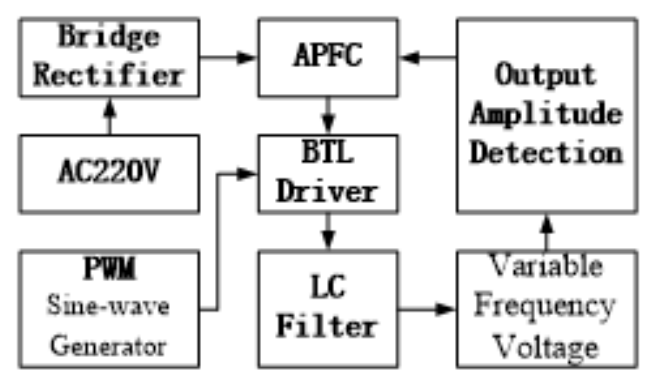

Fig.9 The block diagram of mainframe

In order to enhance power factor of the system, mainframe provides 220V AC which is transformed by APFC mode to sine-wave generator working in BTL mode. For the sake of improving conversion efficiency and facilitating the design of filter, the pulse width of sine-wave generator is invariant. But in order to stabilize output voltage, amplitude detector controls APFC circuit after detecting the output voltage.

Design of variable frequency AC power supply with high power factor

BTL driver is consist of $\mathrm{A}$ and $\mathrm{B}$ driver shown as figure 10.

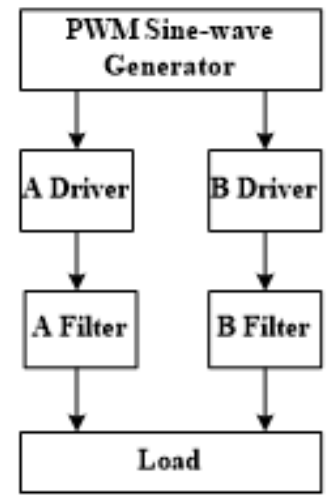

Fig.10 Structure of BTL driver

Sine-wave generator sets a series of PWM pulse on the basis of different voltage value with half cycle of $200 \mathrm{~Hz}$. In order to improve the voltage utilization, duty cycle in peak is designed about $95 \%$, shown as figure 11 .

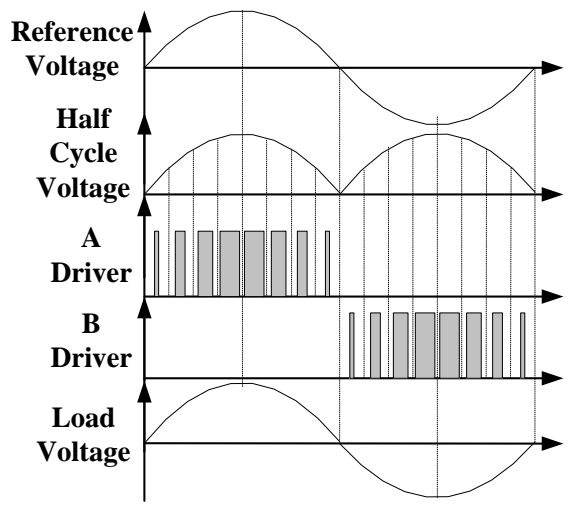

Fig.11 The producing principle of sine wave

When the output voltage is positive half cycle, B driver outputs low level, A driver outputs PWM wave and vice versa. Both ends of the load are sine-wave voltage after LC filter.

Mainframe transforms 190V 250V AC to 370V 400V DC by APFC mode, then provides it to sine-wave generator in BTL mode. Mainframe uses $30 \mathrm{~V}$ change to output stable voltage.

\section{Analysis of experimental results}

Figure 12 and figure 13 is the waveform of extension set's input voltage, current and output voltage when $\mathrm{C}=1 \mu \mathrm{F}, \mathrm{f}=200 \mathrm{~Hz}$ and input voltage are respectively $230 \mathrm{~V}, 250 \mathrm{~V}$. From the figures, when 
frequency increase from $50 \mathrm{~Hz}$ to $200 \mathrm{~Hz}$ and capacitor capacity is small, current is almost invariant, and voltage ripple is small, extension set can work stable.

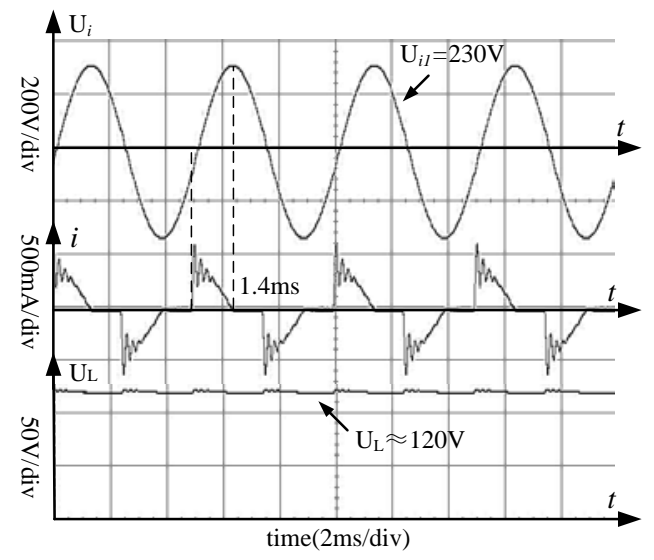

Fig.12 The waveform when input voltage is $230 \mathrm{~V}$

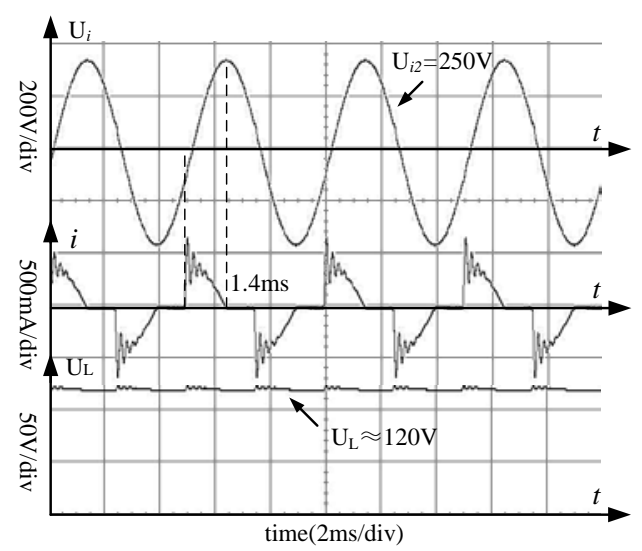

Fig.13 The waveform when input voltage is $250 \mathrm{~V}$

Figure 14 is the measured power curve when input voltage ranges from $220 \mathrm{~V}$ to $250 \mathrm{~V}$. When input voltage increases, load power tend to increase linearly, while power variation is only $2.8 \mathrm{~W}$, constant power characteristic is excellent.

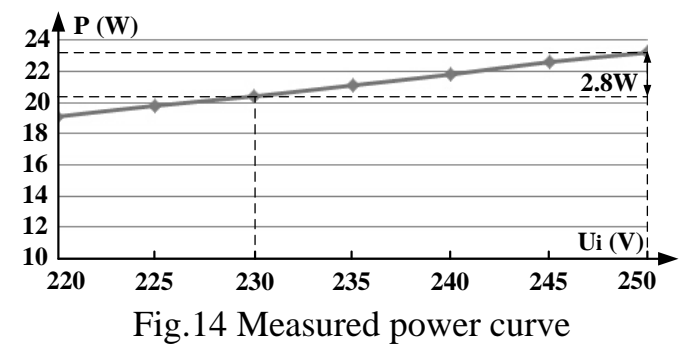

\section{Conclusions}

According to the experimental results, the proposed lighting system takes advantage of efficient main frequency converter to provide variable frequency sine-wave for the system, so efficiency is high and EMI decrease. Extension set adopts simple capacitor step-down mode, it has simple structure, low cost, easy maintenance and so forth, and it can automatically stabilize the power, so it can be widely used in small lighting system with the total power below $5 \mathrm{KW}$.

\section{Acknowledgments}

Corresponding Author: Yonggao Jin, ygao@ybu.edu.cn Tel: 86-13804481200

\section{References}


[1] Liu, K. Gao, Y.H. \& Yan, P. 2011. Electromagnetic compatibility design methods of high-frequency and high-voltage power supply. Chinese Journal of Power Source, 35(10): 1325-1328.

[2] Yu, C.L. Yi, M.X. Tao, J. \& X.S. 2013. A capacitor step-down DC supply with low thermal power consumption. Xiang: Application of Electronic Technique, 39(11): 67-69.

[3] Yeung, Y.P.B. Cheng, K.W.E. \& Law, K.K. 2001. Switched-capacitor based step-down resonant converters. The World of Power Supply, (12): 12-15, 28.

[4] Hao, W.H. Jia, Chen, C. H. Zhang C. \& Wang, Z.H. 2009. A variable step-down conversion ratio switched capacitor DC-DC converter for energy harvesting systems working in intermittent mode. Journal of Semiconductors, 30(12): 103-107.

[5] Su, H. \& Jin Y.G. 2014. Design of capacitor step-down regulated power supply based on current conduction angle adjustable mode. 2014 3rd International Conference on Sustainable Construction Materials and Computer Engineering, Changsha, China, 25 October 2014: Applied Mechanics and Materials. 